\title{
Study of the Effect of Pseudomonas Putida and Funneliformis Mosseae on the Growth and Productivity of Tomato (Solanum Lycopersicum L.) in Senegal
}

\author{
Diaw Demba, \\ Gueye Ndiogou, \\ Sare Idy Carras, \\ Dangue Adiouma, \\ Diop Tahir Abdoulaye,
}

Laboratoire de Biotechnologies des Champignons, Département de Biologie Végétale, Faculté des Sciences \& Techniques, Université Cheikh Anta Diop, Dakar Fann, Sénégal

\section{Doi: 10.19044/esj.2019.v15n6p380 ＵRL:http://dx.doi.org/10.19044/esj.2019.v15n6p380}

\begin{abstract}
In Senegal, the Niayes zone plays an important role in the economy of the country. It is the main horticultural production area. Among the crops cultivated, tomato (Solanum lycopersicum L.) is the second place of horticultural crops. However, this crop is confronted with biotic and abiotic constraints leading to lower yields. Thus, the objective of this study is to evaluate the impact of beneficial microorganisms such as rhizobacteria from the group of fluorescent Pseudomonas (Pseudomonas putida) and arbuscular mycorrhizal fungi (Funeliformis mosseae) on the productivity of tomatoes. Soil samples were taken from the rhizosphere of tomato plants. The bacterial strains were isolated by the method of suspensions dilutions, and then seeded on King B medium. Their identification was carried out by using the MALDITOF mass spectrometer. In order to evaluate the effect of these microorganisms on productivity, an experiment was conducted in the field for three months. An experimental device with three randomize blocks was adopted with four block treatments: T (control), PS1 (Pseudomonas putida), Fm (Funneliformis mosseae) and PS1 + Fm. The results obtained showed that the inoculation of tomato plants with PS1 or in combination with Fm induced the best yields with values exceeding respectively $5 \mathrm{t} / \mathrm{ha}$ and $1.5 \mathrm{t} / \mathrm{ha}$ compared with non-inoculated plants. The yield reductions observed in the case of co-inoculation between Fm and PS1 compared with PS1 treatment alone would suggest an antagonistic effect. These strains of Pseudomonas
\end{abstract}


putida constitute an alternative for the increase of tomato productivity in the Niayes zone.

Keywords: Inoculation, microorganisms, productivity, tomato

\section{Introduction}

The Niayes zone, a strip of land along Senegal's coastline between Dakar and Saint Louis, is an area with high economic potential. It counts for about $60 \%$ of national vegetable production. The tomato (Solanum lycopersicum L.) is among the most important speculations. It is grown in offseason (October to July) and ranks second among horticultural crops after onion. In fact, the cultivation of tomatoes accounts for $20 \%$ of cultivated areas (Fall et al., 2010). This culture is submitted to numerous biotic and abiotic constraints. In view of these factors, it is appropriate to propose a vegetable production route based on the use of beneficial microorganisms such as arbuscular mycorrhizal fungus (AMF) and rhizobacteria belonging to the group of fluorescent Pseudomonas.

Arbuscular mycorrhizae or arbuscular endomycorrhizae are formed by lower fungi that have a wide variety of plant partners including most horticultural plants. The beneficial effects of arbuscular mycorrhizae on plants are well established. Indeed, in exchange for the carbon provided by the plant, the major role of AMF is the improvement of the plant's hydric and mineral nutrition, especially in phosphorus (Feddermann et al., 2010), in nitrogen (López-Pedrosa et al., 2006) and other essential cations such as zinc, copper, manganese and iron (Liu et al., 2000). These minerals are taken from the soil by fungal extrarinary structures and transported to the roots of the plant. In addition to nutritional effects, MAF are biocontrol agents against phytopathogenic agents (Mukerji and Ciancio, 2007).

In addition to AMF, there are bacteria in the soil called Plant Growth Promoting Rhizobacteria (PGPR) or rhizobacteria, which can also have positive effects on plant growth (Ma et al., 2011). This is the case of fluorescent Pseudomonas whose beneficial effects on the plant result from different mechanisms: directs (solubilization of phosphorus, potassium, nitrogen fixation, sequestration of iron by siderophores, production of growth regulators, etc.) or indirect mechanisms such as antibiotic production (Karnwal, 2009).

Thus, the objective of this study is to evaluate the effect of these beneficial microorganisms (Funneliformis mosseae and Pseudomonas putida) on the growth and productivity of tomato in Senegal. 


\section{Materials and methods \\ Bacterial material \\ Isolation}

The isolation of Pseudomonas bacteria was performed by the suspensions-dilutions method. $100 \mathrm{~g}$ of soil were collected at the Center for the Development of Horticulture (Cambérène station, eco-geographical zone of Niayes, Dakar Region, Senegal) in off-season (February). This soil comes from the rhizosphere of fruiting tomato plants. From this sample, $1 \mathrm{~g}$ of sol was suspended in $10 \mathrm{ml}$ of sterile $\mathrm{MgSO} 4,7 \mathrm{H} 2 \mathrm{O}$ 0,1 M. After stirring for 10 minutes using a vortex, decimal dilutions $\left(10^{-1}\right.$ at $\left.10^{-8}\right)$ were performed. For each dilution, $0.1 \mathrm{ml}$ was plated in Petri dishes each containing $10 \mathrm{ml}$ of King $\mathrm{B}$ agar media (KB). Petri dishes are incubated at $28^{\circ} \mathrm{C}$ in the dark.

After 48 hours of incubation, the bacterial colonies were observed under a U.V. lamp at $365 \mathrm{~nm}$. Sixteen isolates producing a fluorescent pigment were selected and purified by streaking on the solid medium KB and then designated (PS1a, PS1b, PS2a, ... and PS10b).

\section{Identification of isolates}

Identification of the isolates was performed using the MALDI-TOF mass spectrometer (Matrix-Assisted Laser Desorption / Ionization Time-OfFlight). The sample of the isolate is then mixed with a matrix on a plate. The matrix / sample mixture will co-crystallize on the plate. This co-crystallized mixture is bombarded by a laser beam, resulting in the ionization and desorption of molecules (MALDI). The ionized molecules will then pass into a flight tube. They are separated according to their mass / charge ratio $(\mathrm{m} / \mathrm{z})$ according to their flight time (TOF). The ions reach a detector which will amplify the translated signal in the form of a characteristic spectrum of each species.

These identified isolates were used for the preparation of the bacterial inoculum in liquid $\mathrm{KB}$ medium with stirring for 24 hours and at $28{ }^{\circ} \mathrm{C}$.

\section{Fungal material}

The fungal material, Funneliformis mosseae, used belongs to the collection of the Mushroom Biotechnology Laboratory of the Cheikh Anta Diop University of Dakar. This strain produced in a greenhouse for three months is maintained by regular cultures in association with a mycotrophic plant, corn (Zea mays) in $1.5 \mathrm{~kg}$ capacity pots. Each pot contains as culture substrate coarse beach sand sterilized at $120^{\circ} \mathrm{C}$ for two hours.

\section{Conduct of culture and experimental device}

The trial was conducted in the field for three months (December to February) at the Experimental Station of the Botanical Garden of the Faculty 
of Science and Technology of the Cheikh Anta Diop University of Dakar. After weeding and tilling the ground, a well-leveled board of dimensions $2 \mathrm{~m}$ lenght and $1 \mathrm{~m}$ wide was made for the nursery. Seeding was done in-line and open furrows spaced $20 \mathrm{~cm}$ apart were plotted at the plank. The seeds, arranged in the furrows at a depth of $1 \mathrm{~cm}$ were covered with a thin layer of sand. To maintain the nursery, the plants were maintained by daily watering at field capacity for four weeks.

For the transplanting of tomato plants from the nursery, a randomized randomized experimental block device was adopted with 2 factors : the endomycorrhizal fungus (without fungus, with Funneliformis mosseae), combined with Pseudomonas (without Pseudomonas, with Pseudomonas putida). This corresponds to a total number of four treatments per block repeated three times. The treatments are: T (Control), PS1 (Pseudomonas putida), Fm (Funneliformis mosseae) and PS1 associated with Fm.

Inoculation was done at the time of transplanting. Each tomato plant was inoculated with $2 \mathrm{ml}$ bacterial suspension of $10^{8} \mathrm{cfu} / \mathrm{ml}$ density and $20 \mathrm{~g}$ mycorrhizal inoculum consisting of the corn root associated culture substrate. The inoculum is introduced into the growing medium near the root system of each tomato plant.

At the end of the experiment, the aerial and root parts of the plants were taken to evaluate the aerial and root biomasses. The yield obtained is the amount of fruit that has been harvested throughout the experiment. It is expressed in tonnes per hectare ( $\mathrm{t} / \mathrm{ha})$.

\section{Results analysis}

The results were analyzed with the SIGMAPLOT software (SIGMASTAT). The data were processed statistically using a parametric approach that is the analysis of variance (ANOVA). The Newman-Keuls test made it possible to compare the averages of the variables measured at the $5 \%$ probability level.

\section{Results}

\section{Bacterial Identification}

The identification of isolates (PS1a, PS1b, PS2a, ... PS10b) using MALDI-TOF mass spectrometry revealed that all isolates belong to the same genus and species according to mass spectra obtained with MALDI Biotyper software. Analysis of these spectra shows that the peaks produced ( $\mathrm{m} / \mathrm{z} 4500$, $\mathrm{m} / \mathrm{z} 5100, \mathrm{~m} / \mathrm{z} 6000, \mathrm{~m} / \mathrm{z}$ 7200) is characteristic of strains of Pseudomonas putida (Fig. 1a, 1b, 1c). 


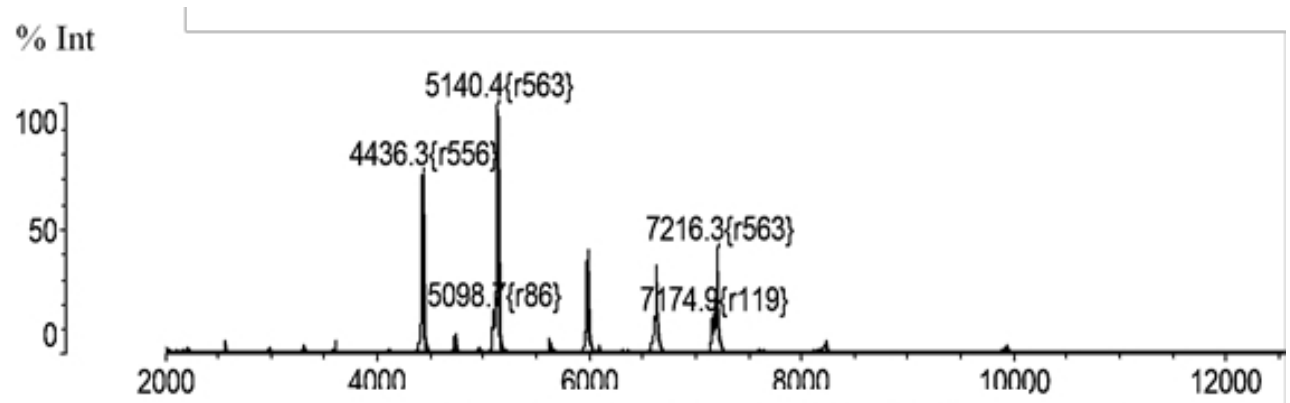

Figure 1a: Mass spectrum of isolate $\mathrm{PS}_{\mathrm{la}} \quad \mathrm{m} / \mathrm{z}$

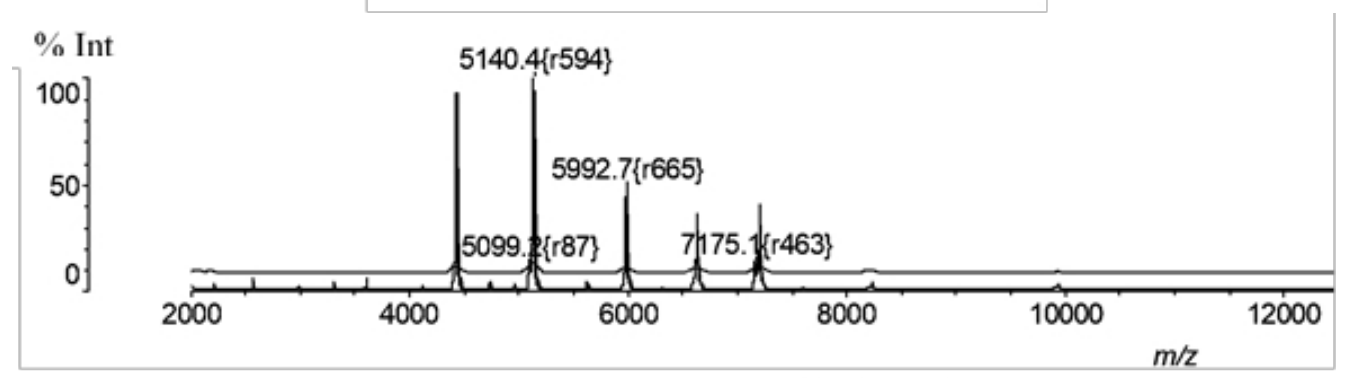

Figure 1b: Mass spectrum of isolate $\mathrm{PS}_{1 \mathrm{~b}}$

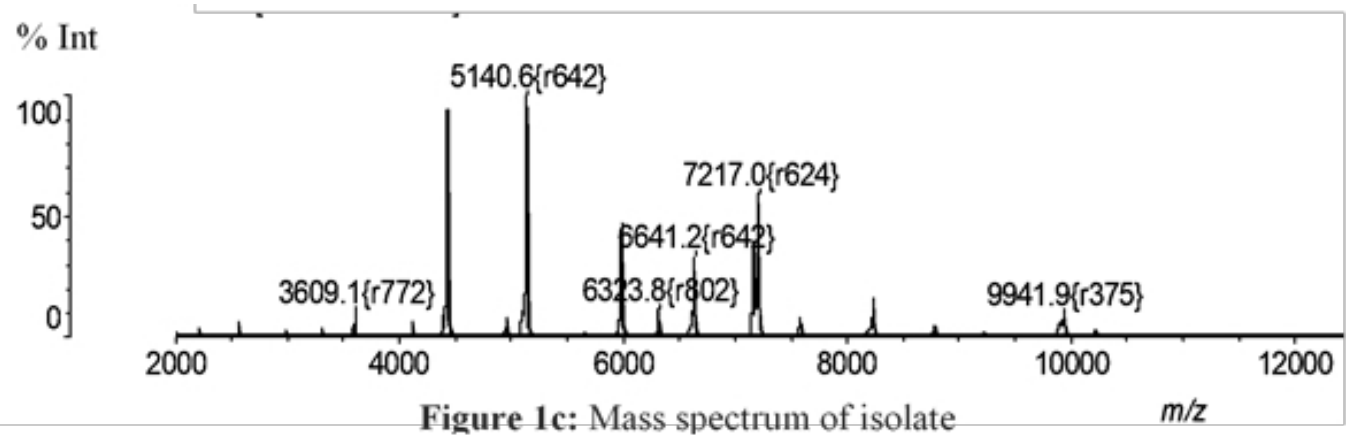

\section{Effect of microorganisms on aerial dry biomass}

Inoculation of tomato plants with the Funneliformis mosseae (Fm) fungus alone did not show a positive effect on aerial dry biomass compared with the control. The largest aerial biomasses are obtained when the plants are inoculated with the bacterial strain Pseudomonas putida (PS1) alone with $23.17 \mathrm{~g}$, followed by the co-inoculation Pseudomonas putida - Funneliformis mosseae with $21.27 \mathrm{~g}$. Nevertheless, these values do not differ significantly from inoculation with the fungus alone or with the control (Fig. 2). 


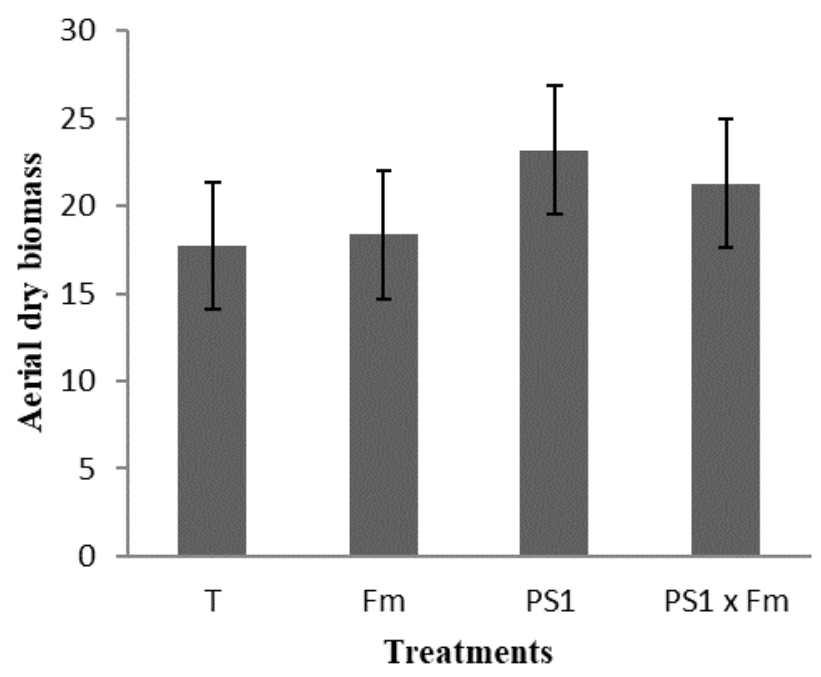

Figure 2: Effect of microorganisms on aerial dry biomass

\section{Effect of microorganisms on dry root biomass}

The dry root biomasses obtained for the different treatments, after 3 months of culture vary from $3.29 \mathrm{~g}$ to $4.36 \mathrm{~g}$. When plants are inoculated with Funneliformis mosseae fungus alone, or in combination with Pseudomonas putida, dry root biomass values are $3.29 \mathrm{~g}$ and $3.45 \mathrm{~g}$, respectively. These values are substantially equal to that obtained for the control. On the other hand, inoculation with Pseudomonas putida alone leads to an increase of dry root biomass up to $4.36 \mathrm{~g}$, but this value is not significantly different from the control or treatment Pseudomonas putida - Funneliformis mosseae (Fig. 3).

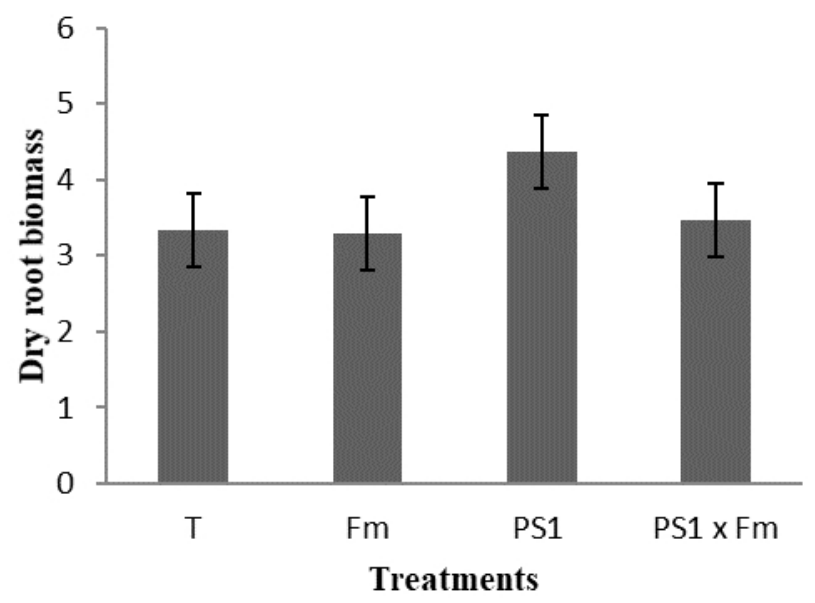

Figure 3: Effect of microorganisms on dry root biomass 


\section{Effect of microorganisms on productivity}

The yield obtained is greater when the plants are inoculated with Pseudomonas putida with $10.18 \mathrm{t} / \mathrm{ha}$. This value is almost twice more important than what obtained by inoculation with Funneliformis mosseae or the control. However, in the case of co-inoculation between Fm and PS1, the yield is $6.71 \mathrm{t} / \mathrm{ha}$; a drop of about $3.5 \mathrm{t} /$ ha compared to PS1 treatment alone.The yield gains obtained, when the plants are inoculated with Pseudomonas putida alone or in association with the Fm mushroom, are respectively $5 \mathrm{t} /$ ha and $1.5 \mathrm{t} /$ ha compared with the uninoculated plants (Fig. $4)$.

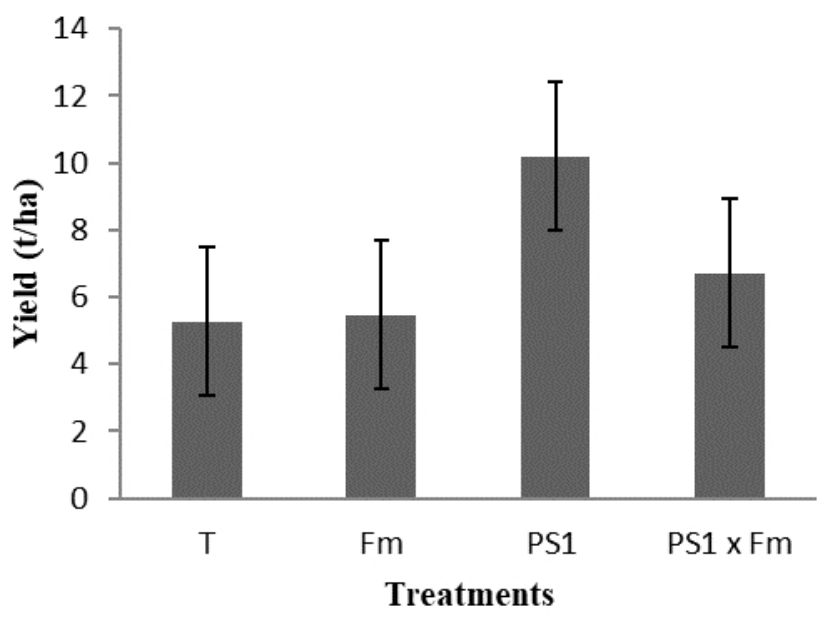

Figure 4: Effect of microorganisms on yield

\section{The gall index}

The results obtained do not show a significant difference for the different treatments. For the different treatments Fm alone, or the coinoculation Pseudomonas putida / Funneliformis mosseae or the control, the indices are between 3 and 4 . This results in the presence of many galls on the roots of tomato plants. On the other hand, the value of the index is less than 3 when the plants are inoculated with Pseudomonas putida alone. This is characterized by the presence of small galls on the roots of tomato plants (Fig. $5)$. 


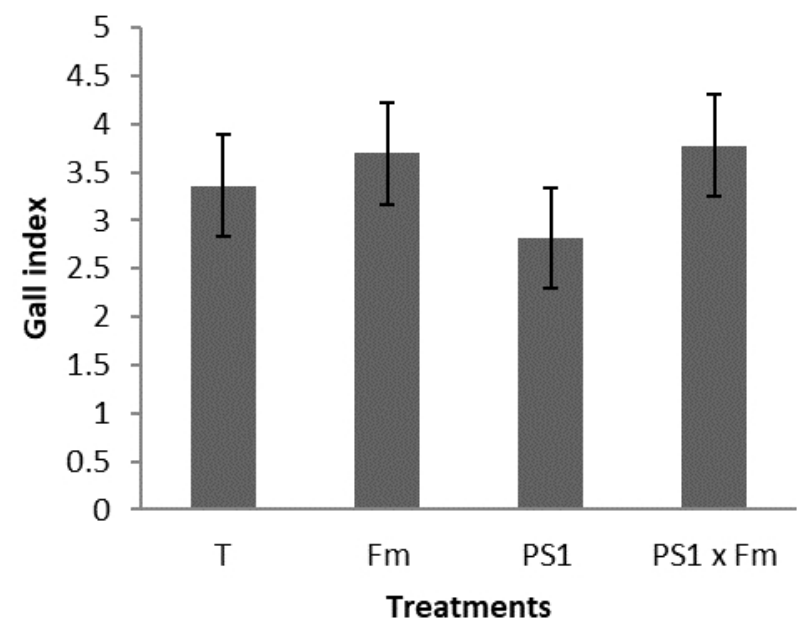

Figure 5: Gall index

\section{Discussion}

The dry root aerial biomasses and the best yields are obtained in tomato plants inoculated with strains of Pseudomonas putida. This increase in yield was obtained in maize with Pseudomonas putida (Adjanohoun et al., 2012). These results are explained by the fact that these rhizosphere bacteria act by stimulating the growth of plants by various mechanisms such as nitrogen fixation, solubilization of trace elements such as phosphate, the synthesis of phytohormones and vitamins (Dobbelaere et al. al., 2003). These positive effects include improved root system development, allowing for better water and nutrient uptake (Siddiqui, 2003).

Inoculation of tomato plants with Funneliformis mosseae has no significant effects on uninoculated controls for growth parameters and yield. These results are in agreement with those of Diatta et al., 2013, who proved that in sesame plants inoculated with fungal mycorrhizal fungi Funneliformis, no significant effect was noted on the yield of sesame seeds. In addition, Haro et al., 2012, inoculating cowpea plants with mycorrhizal fungi, have also shown that there is no significant difference in growth between inoculated and uninoculated plants. In contrast, positive effects were noted in watermelon plants inoculated with Funneliformis mosseae with increased yields (Wang et al. 2008). The response of plants to mycorrhizal inoculation may be justified by host preference for endomycorrhizal fungi (Diop et al., 2003).

Co-inoculation between Pseudomonas putida and Funneliformis mosseae resulted in a slight increase in aerial, root dry weight and yield with no significant difference from the uninoculated control. Indeed, this combination leads to an increase in the growth of tomato plants in a synergistic way thanks to a better improvement of the mineral nutrition of tomato plants 
(Gamalero et al., 2004). This effect is known from the genera Funneliformis and Pseudomonas; by the production of phytostimulant compounds by Pseudomonas and or the increase of water absorption by the plant thanks to the fungus (Avis et al., 2008). However, it is important to note that there are always interactions between soil microbial groups, with effects that may be neutral, positive or negative for the plant (Whipps, 2001). These negative effects could cause this yield reduction in the case of the association between PS1 and Fm compared to the inoculation of plants with PS1 alone. The mycorrhizal fungus Funneliformis mosseae therefore has an antagonistic effect on Pseudomonas putida. And these results can be explained by the fact that certain mycorrhizal fungi seem to inhibit the formation of biofilms of certain beneficial bacteria (Peres De Carvalho et al., 2015) on the fungal hyphae; thus making it difficult to colonize roots and hyphae.

Tomato plants inoculated with Pseudomonas putida have root nematodes with low indices between 2 and 3. Pseudomonas strains are able to control pathogens via the production of antibiotics, siderophores (Shivakumar, 2007) hence the low indices gall. Inoculations with the Fm fungus alone or coinoculation between Fm and Pseudomonas putida show a strong presence of root-knot nematodes was noted on the roots of tomato plants; which would be the source of low yields. These effects may be explained by the fact that certain arbuscular mycorrhizal fungi in symbiosis with plants may cause changes in the composition and activity of the microflora, which may have a depressive or stimulating effect on the development of microorganisms such as nematodes (Kaznelson et al., 1992).

\section{Conclusion}

Inoculation of tomato plants with Pseudomonas putida strains alone has positive effects on tomato growth and productivity with yields exceeding $5 \mathrm{t} /$ ha compared to uninoculated tomato plants. However, in the case of the association between Fm and PS1, this yield decreases to $1.5 \mathrm{t} /$ ha, a drop of $3.5 \mathrm{t} / \mathrm{ha}$. This would suggest the antagonistic effect of the mycorrhizal fungus on Pseudomonas putida. On the other hand, inoculation with the Fm mushroom alone did not have any significant effects on productivity. This can be explained by the presence of root-knot nematodes on the roots of tomato plants. The response of tomato plants to inoculation depends on the type of microorganism used. The integration of these rhizosphere bacteria in agricultural techniques could be an interesting alternative for an increase in tomato productivity in the Niayes zone.

\section{References:}

1. Adjanohoun, A., Noumavo, PA., Sikirou, R., Allagbe, M., GotoechanHodonou, H., Dossa, KK., Yehouenou, B., Glelekakaï, R., Baba- 
Moussa, L. (2012). Effets des rhizobactéries PGPR sur le rendement et les teneurs en macroéléments du maïs sur sol ferralitique non dégradé au Sud-Bénin. Int. J. Biol. Chem. Sci. 6(1): 279-288.

2. Avis, TJ., Gravel, V., Antoun, H., Tweddell, RJ. (2008). Multifaceted beneficial effects of rhizosphere microorganisms on plant health and productivity. Soil Biol. Biochem. 40, 1733-1740.

3. Diatta, MB., Manzo, OL., Diouf, PRM., Diop, T. (2013). Effets de l'inoculation mycorhizienne sur le sesame (Sesamum indicum L.) en conditions naturelles. Int. J. Biol. Chem. Sci. 7(5): 2050-2057.

4. Diop, TA., Wade, TK., Diallo, A., Diouf, M., Gueye, M. (2003). Solanum Cultivar Responses to Arbuscular Mycorrhizal Fungi: Growth and Mineral Status. African Journal of Biotechnologies, 2: 429-443.

5. Dobbelaere, S., Vanderleyden, J., Okon, Y. (2003). Plant growth promoting effects of diazotrophs in the rhizosphere. Plant Sci. 22: 107149.

6. Fall, AA., David-Benz, H., Huat, J., Wade, I. (2010). Tomate locale et production de concentrés : la force des contrats entre paysans et industrie. In : L'agriculture sénégalaise à l'épreuve du marché. Editions Karthala, 197-215.

7. Feddermann, N., Finlay, R., Boller, T., Elfstrand, M. (2010). Functional diversity in arbuscular mycorrhiza - the role of gene expression, phosphorous nutrition and symbiotic efficiency. Fungal Ecol 3: 1-8.

8. Gamalero, E., Trotta, A., Massa, N., Copetta, A., Martinotti, MG., Berta, G. (2004). Impact of two fluorescent pseudomonads and an arbuscular mycorrhizal fungus on tomato plant growth, root architecture and $\mathrm{P}$ acquisition. Mycorrhiza 14, 185-192.

9. Gravel, V., Antoun, H., Tweddel, RJ. (2007). Growth stimulation and fruit yield improvement of greenhouse tomato plants by inoculation with Pseudomonas putida or Trichoderma atroviride: Possible role of indole acetic acid (IAA). Soil Biology and Biochemistry 39: 19681977.

10. Haro, H., Sanon, HB., Diop, I., Kane, A., Dianda, M., Houngnandan, P., Neyra, M., Traore, A. (2012). Réponse à l'inoculation mycorhizienne de quatre variétés de niébé [Vigna unguiculata (L.) Walp.] cultivées au Burkina Faso et au Sénégal. Int. J. Biol. Chem. Sci. 6(5): 2097-2112

11. Karnwal A. (2009). Production of indole acetic acid by fluorescent Pseudomonas in the presence of L-Tryptophan and rice root exudates. J. Plant Pathol. 91: 61-63. 
12. Kaznelson, A., Rouatt, BN., Peterson, FA. (1992). The rhyzosphere effect of mycorhizal root of yellow birch seedlings. Can. J. Bot., 40: 77-382.

13. Liu, A., Hamel, C., Hamilton, RI., Ma, BL., Smith, DL. (2000). Acquisition of $\mathrm{Cu}, \mathrm{Zn}, \mathrm{Mn}$ and Fe by mycorrhizal maize (Zea mays L.) grown in soil at different $\mathrm{P}$ and micronutrient levels. Mycorrhiza 9: 331-336.

14. López-Pedrosa, A., González-guerrero, M., Valderas, A;, AzcónAguilar, C., Ferrol, N. (2006). GintAMT1 encodes a functional highaffinity ammonium transporter that is expressed in the extraradical mycelium of Glomus intraradices. Fungal Genetics and Biology 43: 102-110.

15. Ma, Y., Prasad, MNV., Rajkumar, M., Freitas, H. (2011). Plant growth promoting rhizobacteria and endophytes accelerate phytoremediation of metalliferous soils. Biotechnology advences 29: 248-258.

16. Mukerji, KG., Ciancio, A. (2007). Mycorrhizae in the integrated pest and disease management. In: Ciancio A, Mukerji KG. (eds) General concepts in integrated pest and disease management. Springer, The Netherlands, 1: 245-266.

17. Peres De Carvalho, MP., Turck, P., Abraham, WR. (2015). « Secondary metabolites control the associated bacterial communities of saprophytic basidiomycotina fungi ». Microbes and Environments 30 (2) : 196-198.

18. Shivakumar, B. (2007). Biocontrol potential and plant growth promotional activity of fluorescent pseudomonads of western ghats. Master of Science (Agriculture). In Agricultural Microbiology.

19. Siddiqui, ZA. (2003). PGPR : Prospective biocontrol agents of plant pathogens. In Siddiqui Z.A., Biocontrol and Biofertilization, 2006, springer, Netherlands, 313p.

20. Wang, C., Li, X., Zhou, J., Wang, G., Dong, Y. (2008). Effects of Arbuscular Mycorrhizal Fungi on Growth and Yield of Cucumber Plants. Communications in Soil Science and Plant Analysis 39: 3-4, 499-509.

21. Whipps, JM. (2001). Microbial interactions and biocontrol in the rhizosphere. In Journal of Experimental Botany 52: 487-511. 